\title{
Inexpensive and Accurate Measuring Device for Water Constitute in Oil
}

\author{
M. Habli*1, M. Meribout ${ }^{1}$, A. Al-Naamany ${ }^{1}$, K. Al Busaidi² \\ ${ }^{1}$ Electrical \& Computer Engineering Department, Sultan Qaboos University, P.O. Box 33, Muscat 123, Oman \\ 2 Petroleum Development Oman, P.O. Box 81, Muscat 113, Oman
}

Received 14 July 2004; accepted 24 October 2005

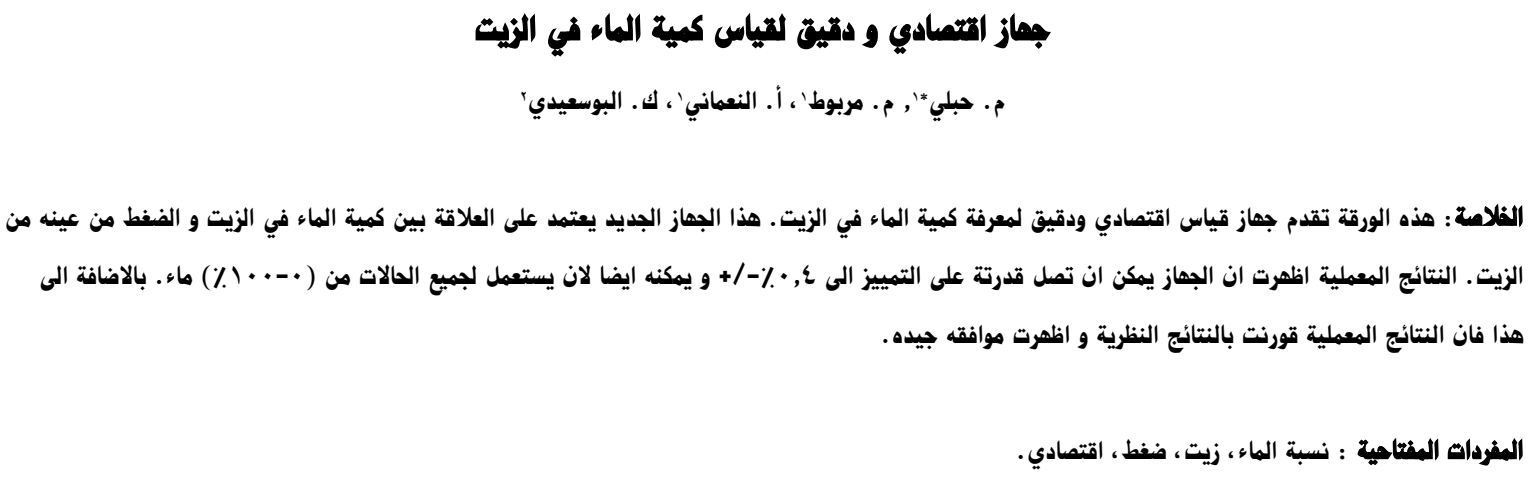

Abstract:This paper presents an inexpensive and accurate measuring device for water constitute in oil. The new device is based on the relationship between the water constitute in oil and the pressure of a sample from the oil. Experimental results show that the device can attain a very high resolution that can reach up $+/-0.4 \%$ and it can be used to measure a full range of water percentage levels (0-100\%). Experimental results showed good agreement with theory.

Keywords: Water percentage, Oil, Pressure, Inexpensive measuring device

\section{Introduction}

Oil wells, in general, produce oil, water, and gas. Knowing the percentage of water in oil is very important for oil production. Oil from nearby wells is carried via pipelines into a collection station. Basic Sediment and Water (BS \& W) devices are usually used to determine the percentage of the water in the produced oil. Conventional BS \& W devices are based on measuring the capacitance or impedance characteristics of the oil (Smit, et al. 1998; Lucas, 1994). However, such devices cannot be used in a full range of water percentage $(0-100 \%)$. Other devices such as radioactive and microwave (Shaofan, 1994; Beckwith, et al. 1981) are harmful and require a special operation procedure. Fiber optic sensors (Betta, et al, 1993; Giallorenzi, et al. 1986; Grattan, 1987) are also available. However, these devices are expensive. In this paper we are reporting experimental results for a new, user friendly, and accurate off-line device that can determine the water constitute in oil. The experimental results show that the device can attain a very high resolution up to $+/-$ $0.4 \%$ and it can be used to measure a full range of water percentage levels (0-100\%). In addition, the experimental results were compared with the theoretical ones and showed a good agreement.

*Corresponding author's e-mail: mhabli@squ.edu.om

\section{Proposed Water-Cut Measurement Method}

The proposed measurement method of the water-cut in a mixture of oil and water is based on the pressure of a sample from the mixture. Consider the system in Fig. 1. The system consists of an apparatus where the pressure of a liquid sample can be measured. The needed sample from a liquid is of a fixed quantity of height $H_{s}$. In principle, for a water and oil mixture, the mixture sample will consist of heights $\mathrm{H}_{\mathrm{o}}$ and $\mathrm{H}_{\mathrm{w}}$, respectively:

$\mathrm{H}_{\mathrm{o}}+\mathrm{H}_{\mathrm{w}}=\mathrm{H}_{\mathrm{s}}$

where,

$\mathrm{H}_{\mathrm{o}}=$ height/level of water

$\mathrm{H}_{\mathrm{w}}=$ height/level of oil

The pressures of the oil and water are:

$$
\begin{aligned}
& P_{o}=\rho_{0} H_{o} g \\
& P_{w}=\rho_{w} H_{w} g
\end{aligned}
$$

where,

$\mathrm{P}=$ pressure, $\mathrm{kPa}$

$\mathrm{g}$ = gravitational acceleration, $\mathrm{m} / \mathrm{s}^{2}$ 
$\mathrm{H}=$ height/level, m (Pressure Head);

$\rho=$ density, $\mathrm{kg} / \mathrm{m}^{3}$

The subscripts ( $o, w$ and $s$ ) stand for oil, water and sample, respectively.

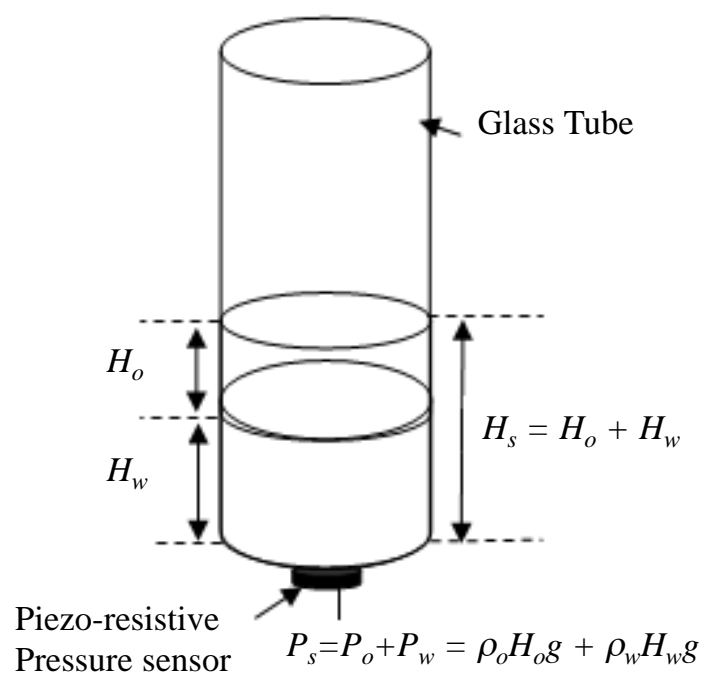

Figure 1. A pressure measuring apparatus

The total pressure $P_{t}$ at the bottom of the container is equal to:

$\mathrm{P}_{\mathrm{t}}=\mathrm{P}_{\mathrm{o}}+\mathrm{P}_{\mathrm{w}}+\mathrm{P}_{\mathrm{a}}$

where $P_{a}$ is the atmospheric pressure. Subtracting $P_{a}$ from (4) yields:

$\mathrm{P}_{\mathrm{s}}=\mathrm{P}_{\mathrm{o}}+\mathrm{P}_{\mathrm{w}}$

$P_{s}$ is the pressure of the mixture sample which reflects the heights or the fractions of both oil and water in the sample. This system can be used to indicate the fractions of water and oil for different mixtures.

Substituting Eqs. (2) and (3) in Eq. (5) yields:

$P_{s}=\rho_{0} H_{o} g+\rho_{w} H_{w} g$

Equations (1) and (6) are two independent equations with two unknowns, $H_{o}$ and $H_{w}$.

The sample quantity $H_{s}$ in Eq. (1) is known and fixed. On the other hand, the sample pressure $P_{s}$ in Eq. (6) is the measured pressure. For known $\rho_{o}$ and $\rho_{w}$, it is possible to solve Eqs. (1) and (6) for $H_{o}$ and $H_{w}$ as:

$H_{o}=\frac{\frac{P_{s}}{g}-\rho_{w} H_{w}}{\rho_{o}}$

and
$\mathrm{H}_{\mathrm{w}}=\mathrm{H}_{\mathrm{s}}-\mathrm{H}_{\mathrm{o}}$

This device can also be used to find the densities of the oil and water samples $\rho_{o}$ and $\rho_{w}$, respectively, from the pressures of two samples of known heights. For example, Eq. (6) can be written for the first sample as:

$P_{s 1}=\rho_{0} H_{o 1} g+\rho_{w} H_{w 1} g$

Similarly, for the second sample, Eq. (6) can be written as:

$P_{s 2}=\rho_{o} H_{o 2} g+\rho_{w} H_{w 2} g$

Equations (9) and (10) can be solved for:

$\rho_{\mathrm{w}}=\frac{\frac{\mathrm{P}_{\mathrm{s} 2}}{\mathrm{~g}}-\rho_{\mathrm{o}} \mathrm{H}_{\mathrm{o} 2}}{\mathrm{H}_{\mathrm{w} 2}}$

and

$\rho_{\mathrm{o}}=\frac{\frac{\mathrm{P}_{\mathrm{s} 1}}{\mathrm{~g}}-\frac{\mathrm{H}_{\mathrm{w} 1}}{\mathrm{H}_{\mathrm{w} 2}} \frac{\mathrm{P}_{\mathrm{s} 2}}{\mathrm{~g}}}{\mathrm{H}_{\mathrm{o} 1}-\frac{\mathrm{H}_{\mathrm{w} 1} \mathrm{H}_{\mathrm{o} 2}}{\mathrm{H}_{\mathrm{w} 2}}}$

It should be noted that this device is an off-line measuring instrument. In order to determine the water-cut in a flow, a sample from the flow is needed. This can be taken automatically from a side pipe through a valve that can close and open automatically by a switch or from a base station computer command. From the pressure of a known amount of the flow, we can determine the percentage of water in oil.

\section{Experimental Setup}

The experimental setup consisted of a piezo-resistive pressure sensor. The sensor was attached to the bottom of an apparatus to measure the pressure of a sample. The output of the sensor was connected to an amplification circuit as shown in Fig. 2. The sample height, $H_{s}$, for all experiments was set to $25 \mathrm{~cm}$. The pressure sensor that was used in the experiments was a differential type, i.e. the output of the sensor indicates $P_{s}$ as in Eq. (5).

Figure 3 shows a photo for the experimental setup. The experimental samples were prepared using tap water and motor oil.

\section{Experiments}

A number of experiments were conducted to test the accuracy and the capability of the device. In the first experiment, a full range test was conducted starting from a $25 \mathrm{~cm}$ water level and no oil and ending with no water 


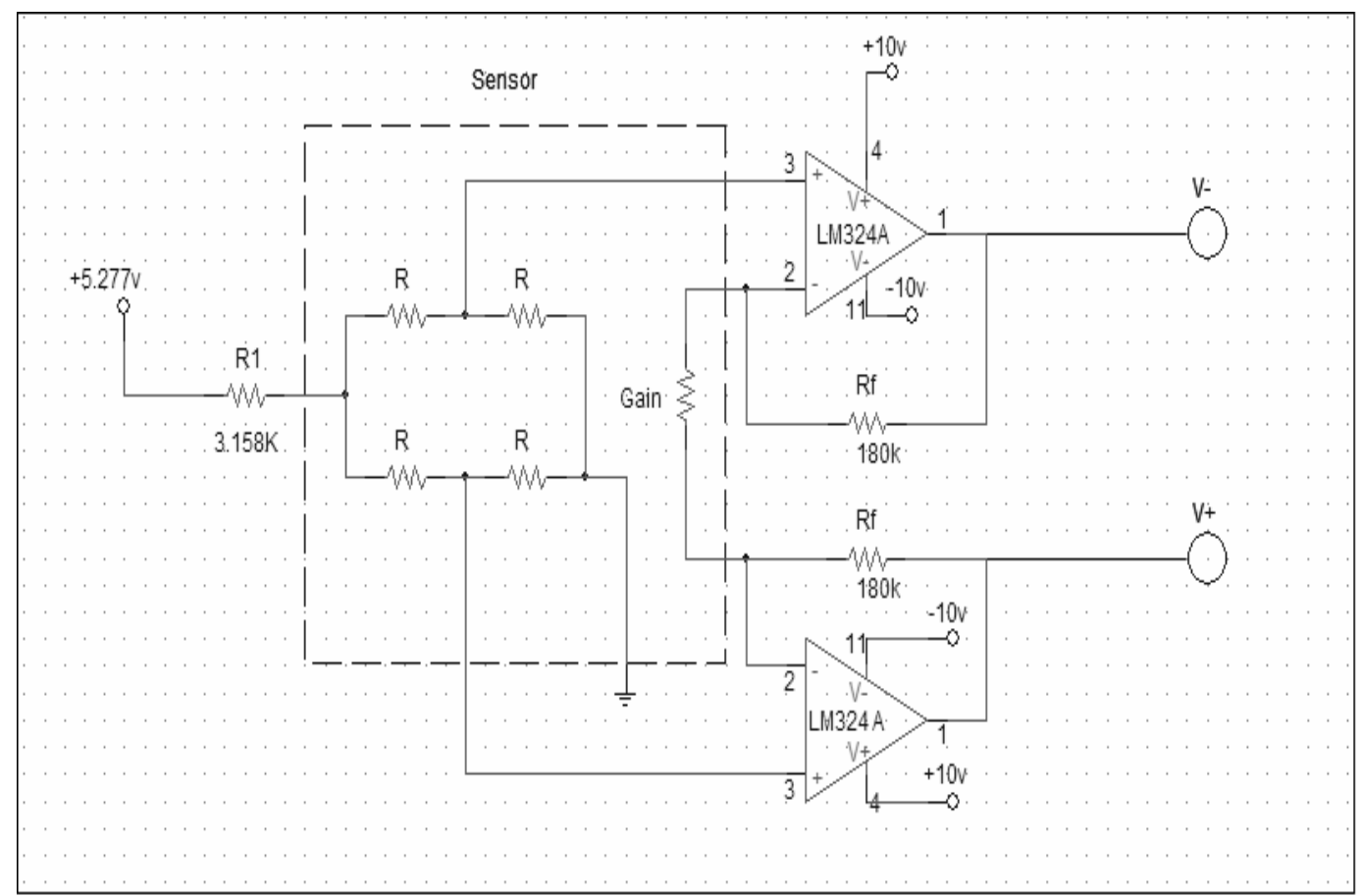

Figure 2. The piezo-resistive pressure sensor and its amplification circuit

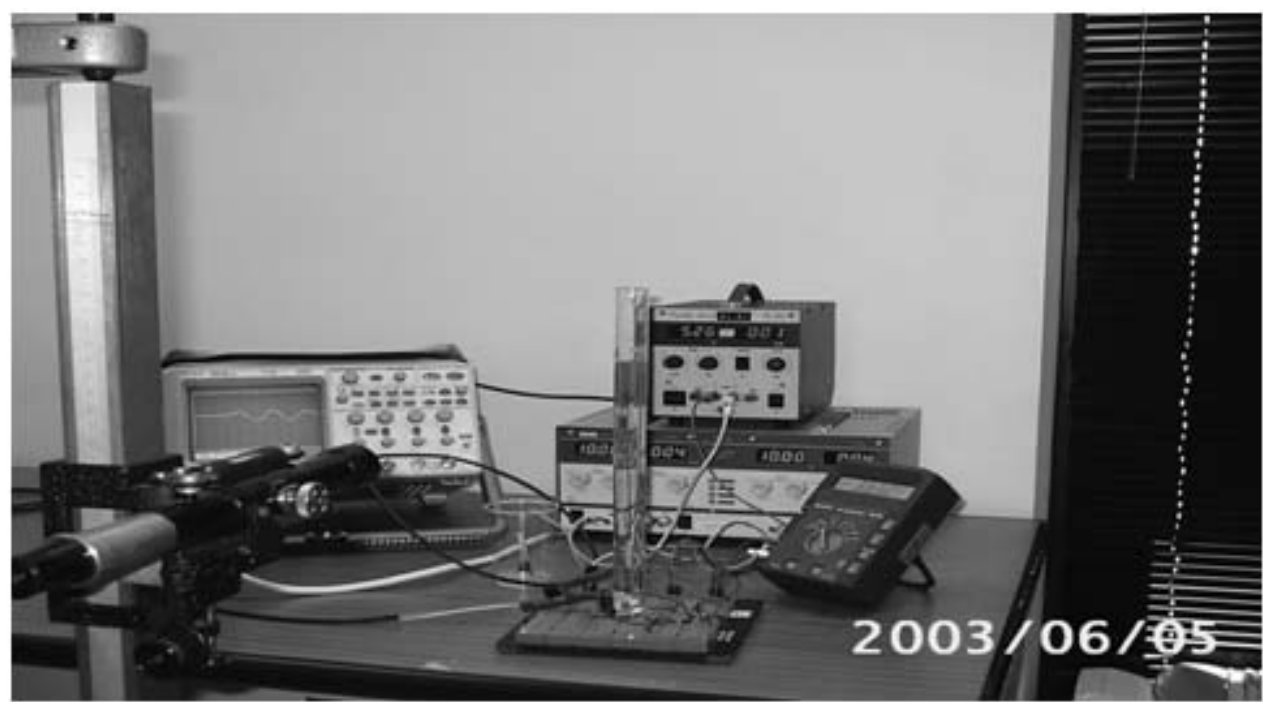

Figure 3. Experimental set up

and a $25 \mathrm{~cm}$ oil level with $1 \mathrm{~cm}$ increments. Theoretical results were deduced from the equations presented in Section 2.0 and compared with the experimental results. For the theoretical analysis, an oil density of $\rho_{o}=0.87$ $\mathrm{gm} / \mathrm{cm}^{3}$ and a water density of $\rho_{w}=1.104 \mathrm{gm} / \mathrm{cm}^{3}$ were used. Figure 4 shows both the theoretical and experimental results. The data indicate that since oil has a less density, the pressure dropped as the oil level increased. The results show almost a linear relation between the oil level and the voltage.

The second experiment was designed to test the accuracy of the device and if it can detect small changes in the mixture. This experiment began with a $25 \mathrm{~cm}$ water level and no oil. The oil in the mixture was then increased from zero to $0.8 \mathrm{~cm}$ using $0.1 \mathrm{~cm}$ increments. The results of measurements are shown Fig. 5. From these results, it is clear that the device can detect the $0.1 \mathrm{~cm}$ change in the $25 \mathrm{~cm}$ mixture. The $0.1 \mathrm{~cm}$ step is equivalent to $+/-0.4 \%$ change in the oil concentration in the mixture. Therefore, it is possible to deduce that the device has a resolution of at least $+/-0.4 \%$.

A third experiment was conducted and aimed also to test the accuracy of the device within another range of oil and water mixture. The range taken was from $20 \mathrm{~cm}$ water and $5 \mathrm{~cm}$ oil mixture to $19 \mathrm{~cm}$ water and $6 \mathrm{~cm}$ oil mixture in increments of $0.1 \mathrm{~cm}$. The results are shown in Fig. 6 . In the fourth experiment, another mixture range was taken 
The Journal of Engineering Research Vol. 3, No. 1 (2006) 63-68

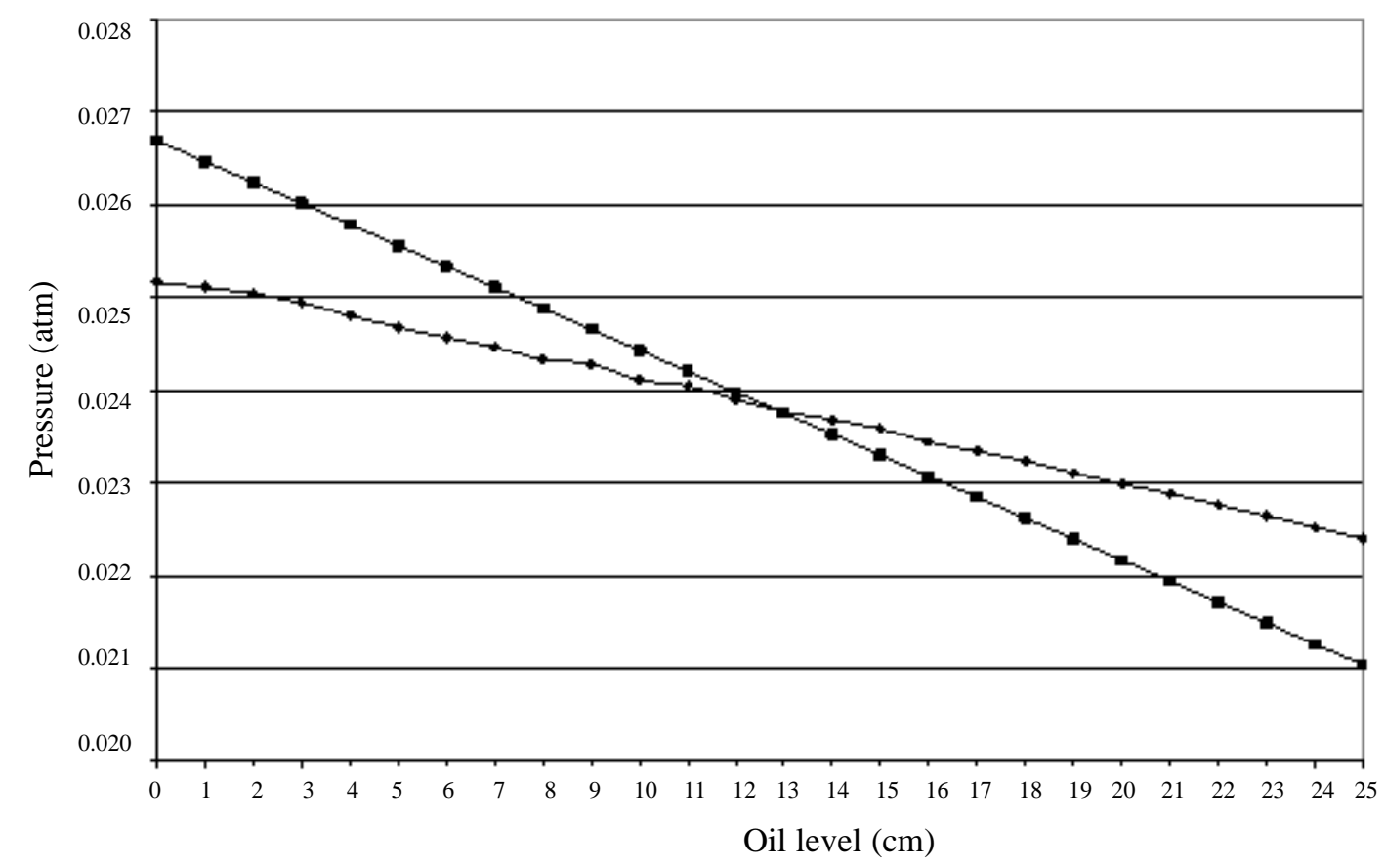

Figure 4. Oil level versus pressure for both the theoretical and experimental results (a Theoretical, Experimental) for full range of oil

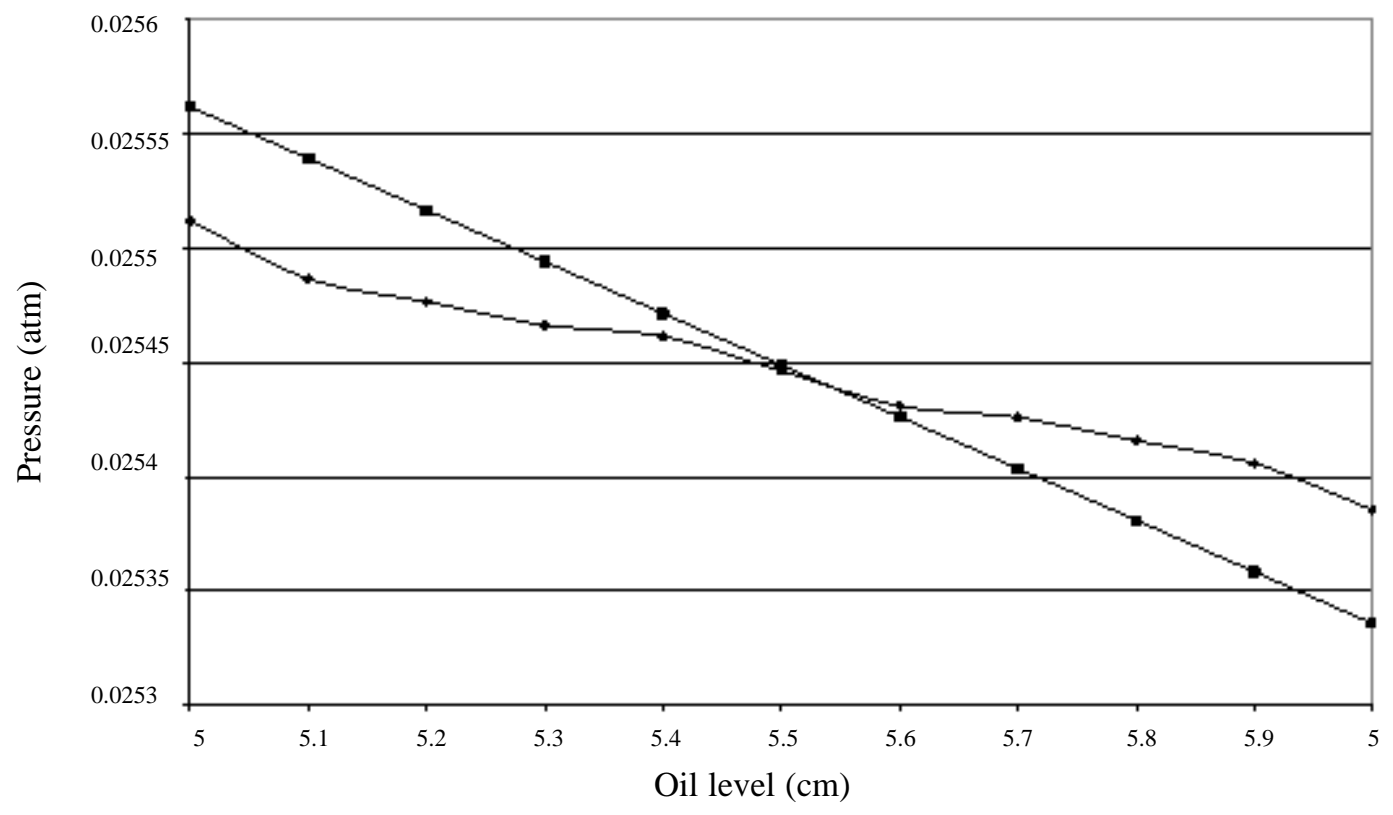

Figure 5. Oil level versus pressure for both the theoretical and experimental results (- Theoretical, Experimental) for 5 to $6 \mathrm{~cm}$ range of oil

from $5 \mathrm{~cm}$ water and $20 \mathrm{~cm}$ oil stand to $3 \mathrm{~cm}$ water and 22 $\mathrm{cm}$ oil stand in increments of $0.1 \mathrm{~cm}$. The obtained results are shown in Fig. 7.

The experiment was conducted using four trials in order to determine the standard error and precision of the system. As an example, Table 1 displays the measurement results of the first experiment alongwith the average and standard error. The overall average precision on the pressure measurement was determined to be approximately $0.083 \mathrm{mAtm}$.

\section{Analysis of the Experimental Results}

Based on the experiments conducted, it was concluded that the device can be used and trained to detect water-cut in an oil and water mixture. The results of the first experiment showed a clear change in the output voltage as the percentage of the oil increased in the mixture. The other three experiments showed that the device can detect small changes at different oil level ranges. In all the ranges considered, the device was able to clearly detect $0.1 \mathrm{~cm}$ 


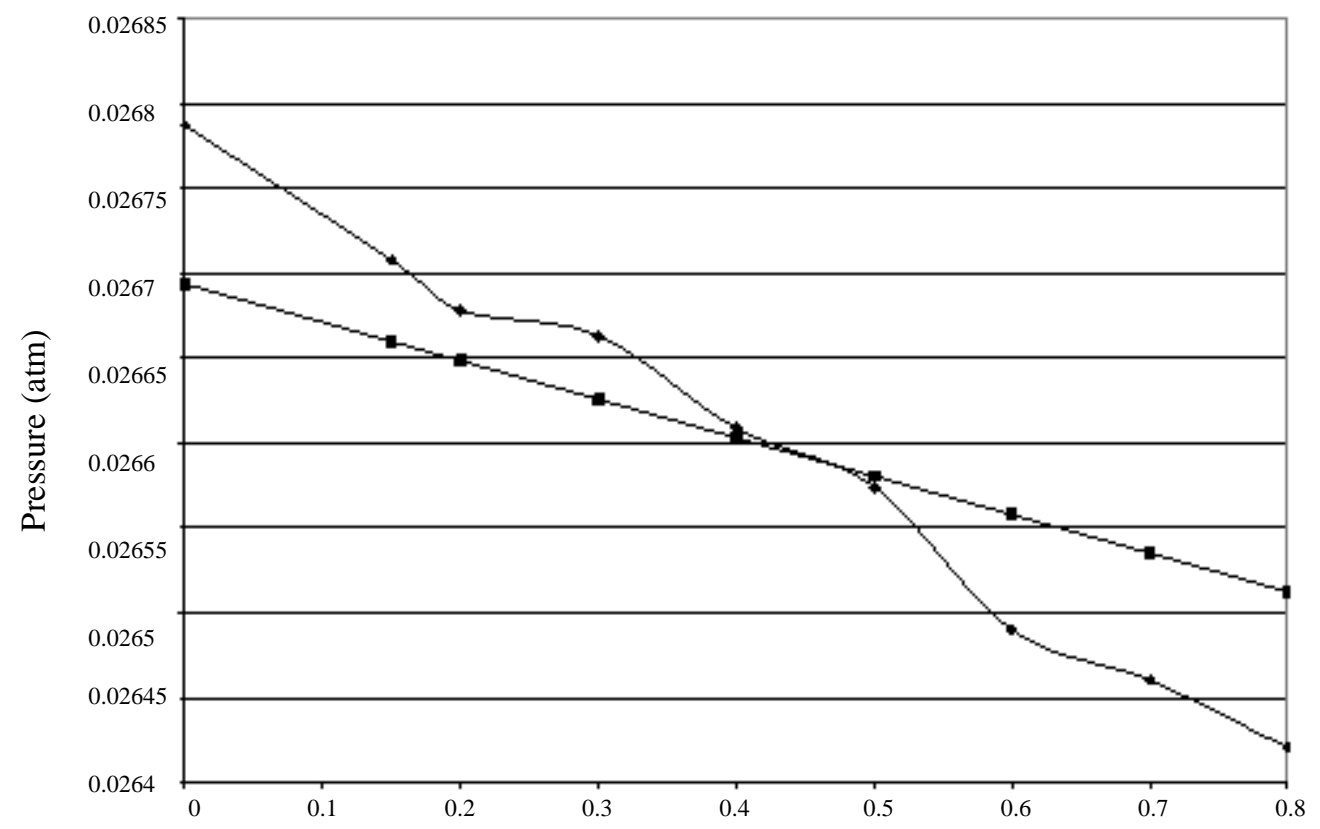

Figure 6. Oil level versus pressure for both the theoretical and experimental results (a Theoretical, Experimental) for 0 to $0.8 \mathrm{~cm}$ range of oil

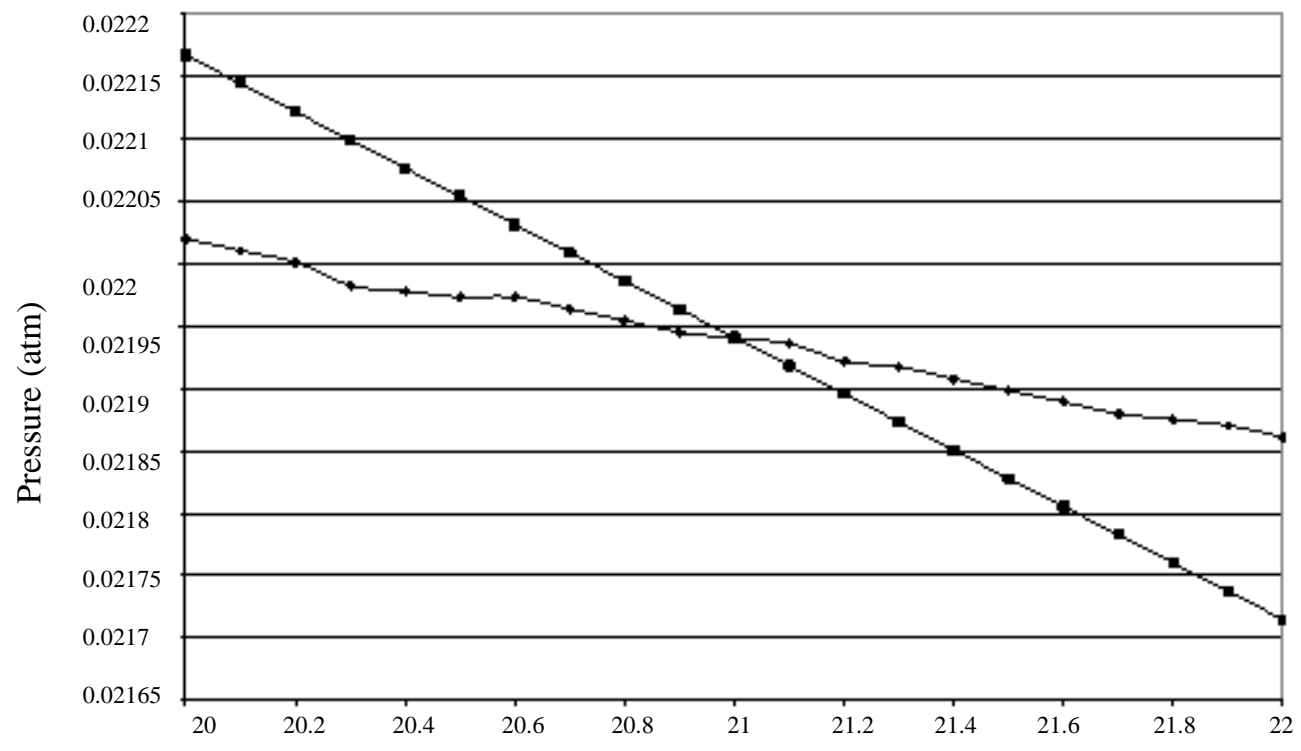

Figure 7. Oil level versus pressure for both the theoretical and experimental results (a Theoretical, Experimental) for 20 to $22 \mathrm{~cm}$ range of oil

change of oil in the mixture. The $0.1 \mathrm{~cm}$ change in a $25 \mathrm{~cm}$ level is equivalent to a measurement resolution of $+/$ $0.4 \%$. One other very important observation is that the device can operate over a full range of water-cut from 0 $100 \%$.

\section{Conclusions}

A number of water-cut measurement devices were evaluated, which included capacitance and conductance devices. Other devices such as microwave, radioactive and fiber optics sensor were either unsafe or expensive cannot be used in the whole water-cut range. The proposed technique, which is based on the relationship between the water-cut in an oil and water mixture and the pressure of a sample from the mixture, is to be very cheap compared to the existing devices. This device is robust, user friendly and can operate in the whole water-cut range. 
Table 1. Measurement results of the first experiment along with the average and standard error values

$\begin{array}{ccccccc}\text { Oil } & & & \text { Pressure (mAtm) } & & \text { Std } \\ \text { (cm) } & \text { Trial 1 } & \text { Trial 2 } & \text { Trial 3 } & \text { Trial 4 } & \text { Average } & \text { Error } \\ 0 & 25.258 & 25.156 & 25.342 & 25.529 & 25.321 & 0.079 \\ 1 & 25.202 & 25.034 & 25.286 & 25.408 & 25.233 & 0.079 \\ 2 & 25.137 & 24.932 & 25.184 & 25.305 & 25.140 & 0.078 \\ 3 & 25.034 & 24.857 & 25.109 & 25.230 & 25.058 & 0.078 \\ 4 & 24.904 & 24.773 & 25.025 & 25.146 & 24.962 & 0.080 \\ 5 & 24.773 & 24.717 & 24.969 & 25.090 & 24.887 & 0.087 \\ 6 & 24.661 & 24.577 & 24.829 & 24.950 & 24.754 & 0.084 \\ 7 & 24.559 & 24.493 & 24.745 & 24.866 & 24.666 & 0.085 \\ 8 & 24.428 & 24.428 & 24.680 & 24.708 & 24.561 & 0.077 \\ 9 & 24.372 & 24.344 & 24.596 & 24.642 & 24.489 & 0.076 \\ 10 & 24.204 & 24.288 & 24.540 & 24.540 & 24.393 & 0.087 \\ 11 & 24.139 & 24.148 & 24.400 & 24.428 & 24.279 & 0.078 \\ 12 & 23.989 & 24.064 & 24.316 & 24.288 & 24.164 & 0.081 \\ 13 & 23.859 & 23.905 & 24.157 & 24.111 & 24.008 & 0.074 \\ 14 & 23.775 & 23.840 & 24.092 & 23.989 & 23.924 & 0.072 \\ 15 & 23.672 & 23.737 & 23.989 & 23.887 & 23.821 & 0.072 \\ 16 & 23.532 & 23.625 & 23.877 & 23.812 & 23.712 & 0.080 \\ 17 & 23.430 & 23.467 & 23.719 & 23.728 & 23.586 & 0.080 \\ 18 & 23.327 & 23.402 & 23.653 & 23.672 & 23.514 & 0.087 \\ 19 & 23.196 & 23.299 & 23.551 & 23.532 & 23.395 & 0.088 \\ 20 & 23.075 & 23.187 & 23.439 & 23.448 & 23.287 & 0.093 \\ 21 & 22.972 & 23.047 & 23.299 & 23.290 & 23.152 & 0.084 \\ 22 & 22.851 & 22.870 & 23.122 & 23.224 & 23.017 & 0.093 \\ 23 & 22.730 & 22.748 & 23.000 & 23.122 & 22.900 & 0.096 \\ 24 & 22.608 & 22.646 & 22.898 & 23.010 & 22.791 & 0.097 \\ 25 & 22.487 & 22.571 & 22.823 & 22.870 & 22.688 & 0.094 \\ & & & & & \text { Average } & 0.083\end{array}$

Experimental results showed that the new, inexpensive, and simple measuring device for water-cut in oil can attain a very high resolution that can reach up $+/-0.4 \%$ and it can be used to measure a full range of water-cut levels ( 0 $100 \%)$.

\section{Acknowledgements}

This work was supported by Petroleum Development Oman (PDO).

\section{References}

Beckwith, T.G., 1981, Mechanical Measurements, Addison Wesley Publishing Co. pp. 445-477.

Betta, G. and D'Apuzzoand, L.M., 1993, "An Intrinsic Optical Fiber Sensor", Imeko TC4, pp. 113-119.

Grattan, K.T.V., 1987, "Recent Advances in Fiber Optic Sensors," Measurement, Vol. 5, pp. 122-134.

Giallorenzi, T.G., 1986, "Optical Fiber Sensors Challenge the Competition", IEEE Spectrum.

Lucas, G.P., 1994, "Flow Rate Measurement in Vertical Oil-water Flows using Conductivity Sensors and a Void Fraction Wave Model," Advances in Sensors for Fluid Flow Measurement, pp. 13/1-13/3.

Smit, Q., Mortimer, B.J.P. and Tapson, J., 1998, "General Purpose Self-tuning Capacitance Sensor [for Oil Recycling and Soil Moisture Measurement Application]," Instrumentation and Measurement Technology Conference, IMTC/98, Vol. 2, pp. 107478.

Shaofan, W.Q.D., 1994, "A High-accuracy Microwave Sensor and Calibration for Measuring Three-phase Saturations in Cores," Instrumentation and Measurement Technology Conference, IMTC/94, Vol. 3, pp. 1273-76.

Shaofan, W.Q.D., 1994, "A Microwave Technique for Measuring Three-phase Saturations in Cylindrical Cores," Precision Electromagnetic Measurements, pp. 71-71. 